four years without presenting any serious anatomic lesions attributable to the alcohol. Between the extremes, there are all gradations in susceptibility, young animals and pregnant ones being generally the most susceptible.

2. 'The experimental reproduction in animals of certain of the more characteristic diseases of human beings, attributable to the abuse of alcohol, such as cirrhosis of the liver, chronic Bright's disease and arteriosclerosis, has not been satisfactorily attained. The most common pathologic condition noted is a fatty metamorphosis affecting especially the cells of the liver, the heart muscle, and the kidneys. 'This lesion soon disappears after stopning the use of the alcohol. Death or necrosis of limited groups of cells in the liver and kidneys may occur, but is inconstant. More common is an acute or chronic catarrhal gastritis, but this, too, is often absent or but slight. Changes in the central nervous system, similar to those in acute alcoholism, as well as certain additional ones, may be present in experimental chronic alcoholism. Hyperemia and small hemorrhages may occur, cspecially in the stomach, the kidneys and the brain. In view of considerable differences in the results reported by different experimenters, and of many still unsolved problems, additional experiments on the pathologic effects of the long-continued use of alcohol and of alcoholic drinks are needed.

3. Alcoholic intoxication increases the susceptibility of animals to many infections, and influences unfavorably the process of immunization. Pregnant rabbits repeatedly intoxicated by alcohol are likely to abort, and to die soon afterward from some accidental infection. Many of their young die a few days after birth.

In conclusion, I wish especially to thank Prof. William $\mathrm{H}$. Welch, who directed this work, for his many suggestions and his encouragement in the performance of these experiments.

This work was aided by a grant from the "Committee of Fifty."

\section{PULMONARY STREPTOTHRICOSIS.}

A REPORT OF TWO CASES AND A REVIFW OF THOSE IIITHERTO REPORTED FROM A CLINICAL STANDPOINT.

\section{THOMAS G. ASHTON, M.D.}

Adjunct Professor of Medicine at the University of Pennsylvania; Visiting Physician to the Philadelphia General Hospital.

$$
\text { AND }
$$

GEORGE WILLIAM NORRIS, A.B., M.D.

Assistant Visiting Physician to the Philadelphia General Iospital, 'hysician to the Phipps' Institute and the Out-patient Department of the Episcopal Hospital. PHILADELPHIA.

It is not our intention in the present paper to discuss the morphology or the classification of the streptothrix. This subject has been very ably considered in the papers of Norris and Larkin, ${ }^{1}$ Flexner, ${ }^{2}$ Warthin and Olney ${ }^{3}$ and others. It may be said, however, that no definite conclusions have been reached. The consensus of opinion seems to be that there are several distinct varieties of steptothrix, and that the various cases reported as instances of streptothricosis have been due to different varicties of this micro-organism.

From a study of the thus far reported cases of pulmonary streptothricosis it scems that the majority of

1. Norrts and Larkin: Jour. of Exp. Med., 1890

2. Flexner: Trans. Assoc. Amer. Phrs., 1898, vol. xlil

3. Wartbin and O!ney: Amer. Jour. of Mer. Sciences, October the cases present the clinical picture of pulmonary tuberculosis. Bronchicetasis is frequently encountered, and hemorrhage is quite a common symptom. The majority of cases ended fatally, of ten as the result of metastasis to different parts of the body, the central nervous system being frequently involved. We have collected only those cases of streptothricosis which showed evidences of pulmonary involvement; numerous cases are on record in which other organs were the seat of the morbid process. Thus, for example, Ucke has reported a case of tonsillitis due to the streptococcus. Of course, it is not proved that this micro-organism was primarily etiologic in all the cases here collected, although in the majority it would stem eminently probable.

The streptothrix belongs to a rather ill-defined class of vegetable micro-organisms which, while in many respects clasely simulating bacteria, yet possess certain features resembling the hyphomycetes. The dividing line between the streptothrix and bacteria is hard to draw, inasmuch as some of the latter, such as the $B$. diphtherice and the $B$. tuberculosis, at times exhibit branching and other characteristics of the former. Flexner says that the streptothrices, like the moulds, develop from spores into "cylindrical, dichotomously-branching threads, which alternately grow into colonies, the appearance of which suggest a mass of radiating filaments (mycelia)." The streptothrix, then, stands in a class between the moulds and the bacteria.

Doubtless one reason why streptothricosis of the lung has not been reported more frequently is that it is not readily demonstrable by the carbol-fuchsin method of staining, and, therefore, unless the sputum is examinerl by the Weigert-Gram method the organism may be overlooked. In a number of the cases which we have collected, the sputum was examined repeatedly for tubercle bacilli by the usual carbol-fuchsin method, with negative results, and it was only when the Gram process was employed that the micro-organism was found. The obvious conclusion is, of course, that all cases of suspected tuberculosis in which the tubercle bacillus is not found should be carcfully examined by the Gram proeess for streptothrix.

The mere presence of the streptothrix in the sputum or in the tissues does, of course, not prove it to have been the primary pathogenic factor; it may be there simply as a secondary infection; that there are cases on record, however, in which this organism played the main and probably sole rôle in the production of organic lesions, we think, has been incontestably shown. It is a well-known fact that the tubercle bacillus tends to produce different pathologic changes, which present different clinical pictures when it is associated with varyincr micro-organisms, and it is quite probable that similar variations occur in streptothricosis when mixed infections exist. From a study of the reported cases, it seerns that in the acute, bronchopneumonic type of streptothricosis, metastasis is quite common. The skin and the brain secm to be the most frequent locations for such processes, but the bones, the peritoneum, the pericardium, the liver, the spleen, the kidney and the bladder at times have also shared in the involvement. Animal inoculations were made in several cases, and in quite a number typical, although not always fatal, lesions were produced. The tendency to metastasis was also well marked in most of the inoculated animals.

Mayer," in his "Bricfe aus Ostasien," mentions having seen ten cases of streptothricosis of the respiratory tract.

4. Mayer: Muenchner med. Wochft.. 1901, p. 1775. 
'The organism was found in the sputum in small yellowish lumps resembling actinomycosis granules; elastic tissue blood and alveolar cells were also present. One case which came to autopsy showed encapsulated gangrenous areas in the right upper lobe of the lung, in which, as also in the pleural cavity, streptothrix could be demonstrated. These cases, occurring, as they did, after a sandstorm, suggested that infection occurred by inhalation. Another case is also mentioned in which apparently well-marked cavity formation healed completely, together with a disappearance of all symptoms.

Streptothricosis of the lung occurs in two forms: 1. The acuto variety, which presents the symptoms of bronchopneumonia, with mucopurulent expectoration, rcllowish or greenish in color, at times hemorrhagic or containing clastic tissue and bespeaking a necrotic process. Later in the course of the disease we may encounter purulent metastases in other parts of the body. Sucin have been reported in the slin by Schcele and Petruschky, ${ }^{5}$ and in the liver, spleen, heart and brain by Engelhardt and Iöhlein." ${ }^{6}$ This form, therefore, presents in the advanced stages the clinical picture of a pyemia and seems to run to an inevitably fatal termination.

The gross pathology of the lungs resembles, to a certain extent, that of tuberculosis, with caseous areas and softening, surrounded by zones of round-cell infiltration


Fig. 1 - Showing rales throughrut chest. A. Amphoric whis pered pectoral râles.

or induration; occasionally multiple abscesses are encountered.

Microscopically, the streptothrix appears as long, fine, lomogeneous, glistening threads, occurring in clumps and exhibiting a true branching, staining poorly and especially irregularly with Gram's stain, and thus, too, on superficial examination, resembling cocci (Fraenkel).?

2. The chronic variety, first described by Flexner ${ }^{2}$ in $189 \%$, presents almost an identical picture with chronic pulmonary tuberculosis. The case here reported showed in the lungs extensive areas of consolidation and necrosis, together with numerous tubercle-like bodies, the latter being also found in the peritoneal cavity.

CASE 1.-W. S., mulatto, aged 22, was admitted to the Philadelphia General Hospital Sept. 7, 1904, on account of inguinal buboes of several weeks' duration, which were the sequelæ of gonorrhea. After undergoing the operations of circumcision and extirpation of the inguinal glands, the patient having a cough and signs of pulmonary apical disease, was transferred to the medical wards.

History.-Father died of unknown cause, mother of pulmonary tuberculosis. There is no history of malignancy or of syphilis. Patient had convulsions in childhood; later measles and diphtheria. He had chancroid of the penis fourteen

5. Scheele and Petruschky: Nevt. med. Wochft., 1897.

6. Engelharđt and Löhleln : Ieut. Arch. f. klin. Med., vol. $\operatorname{lxx\nabla }$ p. 118 .

7. Fraenkel: Patbologie und Therapie der Lungenkrankheiten, months ago. He uses alcohol in moleration, but does not use tobacco.

Present Illness.-On admission to the medical wards, the patient complained of persistent cough, with copious fetid ex. pectoration, and of pain in the left side and back.

Examination.-Pulse 90, respirations 35 , temperature 102 F. Dyspnea was marked.

Lungs: There was marked dullness of the left chest, extending from the base up to the seventh rib. There was impairment of resonance at the left apex, anteriorly, at which area a few subcrepitant rales were heard. Posteriorly there was dullness at the left apex, with bronchovesicular expiration and great numbers of mixed râles. Over both bases, anteriorly, laterally and posteriorly, resonance and fremitus were diminished, breath sounds were feeble and distant. Posteriorly, beneath the lower third of the left scapula, there was an area of about two and one-half inches in diameter, over which amphoric respiration, aëgophony, whispered pectoriloquy and moist resonating râles were heard. The entire left chest wàs tender on percussion, and respiratory motion was restricted.

Heart: There was marked accentuation of the secomd sounds at the bases; otherwise examination was negative. Other organs showed nothing abuormal.

Urine: Urine was amber colored, acid, sp. gr., 1024. There was a trace of albumin, no glucose; there were hyaline casts and epithelial débris. It was deficient in amount.

Blood: On several different occasions, this showed a leucocytosis ranging from 9,000 to 13,600 , chiefly of the polymorphonuclear variety.
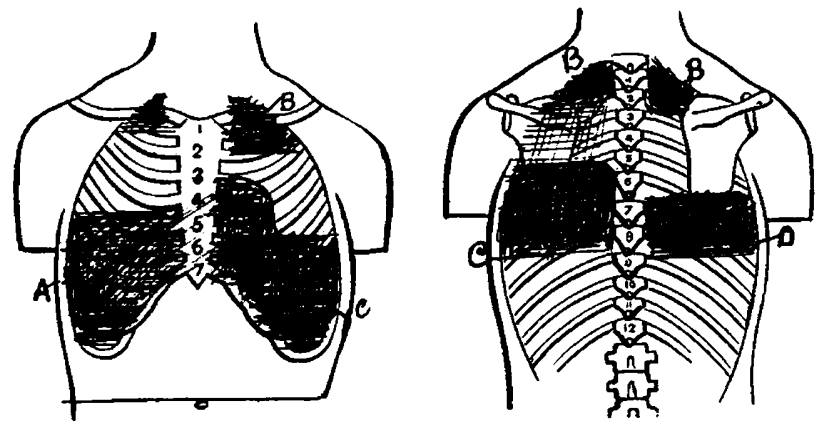

Fig. 2. Imnaired resonance, yocal flemitus, and bronchovesicular expiration; C, distant breath sounds, fremitus and resonance feeble, pain, flat to percussion; $D$, friction sounds.

Course of the Discase.--The patient continued to lose weight and suffered from night sweats, accompanied by cough and large amounts of mucopurulent expectoration. He had several profuse pulmonary hemorrhages, and presented the clinical picture of chronic pulmonary tuberculosis.

Sputum: The sputum was examined for tubercle bacilli on sixteen different occasions, with negative results.

On January 14, Dr. Rosenberger reported the presence of strèptothrix in the sputum.

March 7, the following report was received: "A great variety of bacteria. Organisms corresponding in morphology and tinctorial characters to the $B$. fusiformis of Vincent; cocei resembling pneumococci, a few streptococci, and various other unidentified species. No tubercle bacilli are demonstrable. A streptothrix is also present,"

March 26, a special examination for Pfeiffer's bacillus proved negative.

March 29, the following physical signs were recorded: Clubbing of the fingers which has existed since admission has increased in legree.

Diagnosis.-Until the streptothrix was demonstrated in the sputum the diagnosis had been: "Chronic bilateral fibroid pleuritis, with infiltration and bronchiectasis (or cavity formation) of the left lung, probably tuberculous in origin."

Treatment.-This consisted mainly of stimulation with strychnin and forced feeding. Pain in the left chest was greatly relieved by strapping. Hemoptysis was treated by recumbency, ice bag to the chest, glonoin internally, etc. Santal oil was administered for a time in the hope of lessening ex- 
pectoration and decreasing its fetid character, without any apparent result. Creosote in ascending doses was tried it another time and proved hardly more efficacious.

Diet: During the greater part of the time the patient was given the regular "house diet." In February eggnogs were given between meals, and the patient was encouraged to take as much milk as possible. Soon after beginning improvement was noted, manifesting itself by gain of weight and strength. As soon as the patient was able to be out of bed he was made advice. His temperature, pulse and respiration were still irregular and abnormally high. The nephritis, according to chemical tests, had disappeared, but the patient had never voided more than 48 ounces of urine, the average being about 35 ounces. He had gained considerably in weight and said that he felt strong enough to "work on the farm."

CASE 2.-P. T., Italian, aged 26, a laborer, was admitted to the Philadelphia General Hospital March 23, 1905, with the symptoms of left-sided pleuritis.



Note--In cultures and inoculation columns + signifies positive; $\rightarrow$ signifies negative.

to spend the greater part of the day out of doors on the fire escape.

April 3, patient left hospital at his own request, against

8. Eppinger: Zieglers Beitraege, 1890, vol. IX

9. Sabrazes and Riviere: La Semaine Medicale, 1895.

11. Buchholtz: Zeit. f. Hygiene u. Infectionskrankhelt, 1897, vol. xxiv.

12. Rullmann: Munch, med. Wochft., 1898 and 1902

13. Foulerton: Lancet, 1899.

14. Aoyama and Mfyamoto: Centrlbl. f. Bakteriol., 1901.

15. Musser : Chicago Med. Rec., 1901.
History.-Parents are dead from unknown causes. Four brothers and one sister are well. There is no history of tuberculosis or of malignanti disease in the family. Patient denies

16. Birt and Leishman : Jour. of Hyglene, 1902

17. von Hoke: Prager med. Wochft., 1901.

18. Ucke: St. Petersburger med. Wochft., 1901.

19. von Ziemssen : Verhandl. d. Cong. f. Innere Med., 1898.

20. Riviere: Archiv. Cin. de Bordeaux, 1895, vol. iv, p. 469.

21. Chiari: Zeits. f. Heilkunde, vol. xxi, 1900, No. 10.

22. Ohlmacher: Quoted by Warthin and Olney. 
all history of preceding diseases, even in childhood; also of venereal disease and alcoholism.

I'resent Illness.- This began one month ago with cough, which increased as time went on and was accompanied with mucopurulent expectoration. During this time he lost weight rapidly, developed night sweats and anorexia, and had on two or three occasions attacks of hemoptysis.

Examination.-The patient is a well-developed man, fairly nourished. Yupils are normal. Moebius' sign was present in right eye. Chest is well formed. There is marked clubbing of the fingers.

Heart: There was marked accentuation of the aortic second sound; otherwise negative.

Spleen: This organ was palpable two inches below the costal margin.

Reflexes: The reflexes were apparently normal.

Lungs: There was diminished, delayed and restricted respiratory movement on the left side. Breathing was painful. The lower two-thirds of the left chest was flat on percussion, breath sounds feeble and distant, fremitus absent and resonance diminished. At the left apex, anteriorly, there was bronchovesicular expiration, fremitus and resonance were in creased, and there was cog-wheel inspiration. Posteriorly, there were the same findings, with the exception of the last. named. At the right apex, anteriorly and posteriorly, there was vesiculobronchial expiration. Moist rales were heard from time to time diffusely throughout both lungs, mostly in the left.

Urine: Amber, acid, trace of glucose, no albumin, triple phosphates and amorphous urates.

March 26, 1905, pain in left side, incessant cough and copious, thin, mucopurulent expectoration remain the chief symptoms. There were irregular fever, night sweats (Figs. 1 and $2)$. The foregoing examination led us to believe that we had to deal with a case of pulnonary tuberculosis, with extensive involvement of the pleura. The sputum was examined for tubercle bacilli five times, with negative results. Finally a special examination by Dr. Rosenberger revealed the presence of streptothrix.

May 9, 1905, patient was more dyspneic and emaciated. Clubbing of fingers was more marked. Two urine examinations were entirely negative. Pain in the chest was relieved by strapping. Expectoration was thin, mucopurulent, sometimes almost aqueous in character and not infrequently amounted to over a quart in the course of twenty-four hours, thus pointing strongly toward the existence of a bronchiectasis. No definite plysical signs pointing toward the existence or localization of such a lesion, however, could be made out, but the pleural thickening obscured the breath sounds almost entirely. Exploratory puncture of the left pleural sac yielded negative results. Despite the absence of chemical and microscopic findings in the urine indicative of nephritis, the patient persistently voided very small quantities of urine. This possibly was, in part, due to the large quantity of fluid eliminated in the sputum.

May 29, 1905, patient was in the same condition. He looked very ill, almost cachectic. He took nourishment badly and did not seem much benefited by extra diet of milk and eggs with which he was supplied. It was thought that he would, perhaps, do better if outdoor life could be instituted. To check the excessive expectoration, ascending doses of creosote were administered, without benefit, but the dosage amounted to only fifteen minims thrice daily. Further than this, treatment was stimulating-strychnin, glonoin, digitalis, caffein, etc. Temperature was still irregular.

Blood:

Frythrocptes, 3.560.000; leucocytes, 7,400. Differential count of leucocytes. as follows:



Fosinophiles $\ldots \ldots \ldots \ldots \ldots \ldots \ldots \ldots \ldots \ldots$ 2.5 per cent.

SUMMARY OF CASES.

The accompanving tabulation of twenty-six cases of pulmonary streptothricosis includes the hitherto reported cases, together with the two here recorded. The cases have been compared and contrasted from a clinical standpoint, the preceding articles having dealt almost exclusively with the pathologic and bacteriologic side of the question. From the study of these the following facts may be sunmmarized:

Thirten cases occurred in males, 5 in females, 8 no data. The youngest individual attacked was 12 years, the oldest 70 . The course of the disease varied from one wetk to several years; the majority showed a duration of several months. Seventeen cases had the symptoms of pulmonary tuberculosis, most of these of the chronic variety. Twenty of the cases died- 70 per cent. $-2 \mathrm{im}-$ proved, 2 remained stationary, 2 no data. Cultures and animal inoculations yieided positive results in 11 instances. Hemoptysis was recorded 6 times (23 per cent.) Pure streptothrix infection existed in 14 , in 12 other organisms were coincidently encountered. Tuberculous lesions-old pulmonary scars-were found twice, tubercle bacilli once, scoliosis once. Various methods of treatment have been tried without definite or satisfactory results. The inhalation of medicated vapors had no effect. It would seem rational to presume that the best results would be attained by a therapy such as is employed in the various sanatoria for tuberculosis.

It will be noted that the two cases here reported present numerous features in common. Both suffertd from inflammation of the pleura, accompanied by evidences of marked infiltration. Both expectorated very large amounts of mucopurulent matter and had irregular fever, hemoptysis and symptoms of rasomotor ataxia. Both continuously voided very small quantities of urine -often only from 14 to 16 ounces a day-without marked evidences of nephritis, despite the fact that they were imbibing large amounts of liquid diet. In their response to treatment, however, there was a marked difference in the two cases. The patient in Case 1, in whom the condition had apparently existed for a longer time, improved under treatment and left the hospital. The patient in Case 2, in whom the infection seemed more acute and virulent, became progressively worse. Despite the assertions of the patients to the contrary, we are inclined to believe that the disease had existed in both cases for a much longer period than the histories would lead us to believe; for it is hardly credible that such extensive and massive plemral thickening, even without the bronchiectasis, conld take place in a short time. It is more than likely that, similarly to many cases of pulmonary tuberculosis, the incipient symptoms were of such slight and insidious nature that they were overlooked by the patient.

In closing we would like especially to emphasize our conviction that some of the many apparent cases of pulmonary tuberculosis, in which there is seemingly extensive tissue involvement, often associated with copious expectoration, in which repeated analyses of the sputum fail to reveal tubercle bacilli, if examined with the proper tinctorial agents, would reveal the presence of the streptothrix.

Improved Technic of Spinal Anesthesia.-Le Filliatre states that all the by-effects of spinal cocainization can be avoided by reducing the pressure of the cerebrospinal fluid as a preliminary. Whatever the pressure, he allows the fluid to flow until, instead of spurting, it drips slowly from the needle. He then reinjects always the same amount-10 e.c.-mixed with the anesthetic to be emploved. In an illustrated communication in the Journal de Médecine de Paris, he announces that he has never had a mishap in a total of 452 cases in which he has followed this technic. He thinks the varying rxperiences of others are due to the differences in the pres. sure of the cerebrospinal fluid at the moment of the injection. 